\title{
Deduction of Vacant Technology through Patent Analysis in Disaster-Safety Positioning Technologies
}

\author{
Hangwon Lee and Youngok Kim \\ Department of Electronic Engineering, Kwangwoon University, \\ Seoul 139-701, Korea \\ kimyoungok@kw.ac.kr
}

\begin{abstract}
In recent years, the positioning technologies have been recognized as core technologies for realizing smart space, a ubiquitous society, context awareness, and various location-based services, which are based on the geo-spatial information. Compared to the past research trend that concentrated on the provision of geo-spatial information based on the location, it has been expanded to all industries such as distribution, port logistics, automation, robotics, and safety accident prevention in dangerous areas. Consequently, more objective oriented researches and analyses are required for satisfying growing various needs and it is needed to analyze the existing research and development $(R \& D)$ status on the positioning technology. In this paper, it is intended to understand the existing $R \& D$ status on the positioning technology field from the patent perspective through performing patent analysis on the disaster-safety positioning technology, and thus finds and estimates the future $R \& D$ area by deriving potential promising areas where patent applications are not active. According the results of patent analysis, the technology to improve positioning accuracy through the convergence between IR-UWB and CSS was analyzed as a vacant technology area. In addition, the geo-spatial information estimation technology and the low power positioning technology were concluded as vacant technology areas to be actively researched and developed in the future among required element technologies in order to realize the positioning technology using IR-UWB.
\end{abstract}

Keywords: Ultra Wideband, Chirp spread spectrum, Positioning, Disaster safety, Patent

\section{Introduction}

Recently, information, communication and media, next generation communication network, robot, and knowledge-based ubiquitous sensor network (USN) have been regarded as key areas, which will lead information technology (IT) convergence and highly-advanced IT industry in the future, among various research and development (R\&D) areas selected as growth engines for next generations. In addition, the positioning technology has been noticed as a key technology, which is required to these areas. Particularly, it is even classified as a key technology for acquisition/provision of geo-spatial information on human/material resources, distribution/transportation of construction materials or containers, distribution/ 
transportation in shipyards or production processes, and tracking/controlling of industrial/medical equipment or robots [1].

Figure 1 shows the comparison of ranging accuracy and coverage among various position technologies. As shown in the figure, the global positioning system (GPS) technology utilized in the geo-positional services, such as wireless broadband internet, mobile network technology, and navigation, provides relatively lower geo-positional accuracy, while the coverage is wider relatively [2,3]. Wireless local area network (WLAN) technology provides around 5-10m of geo-positional accuracy, while it can be considered to medium area network service $[4,5]$. However, positioning technology applied in the distribution industry or disaster or safety management areas requires the precise geo-positional accuracy within $3 \mathrm{~m}$ at least, and thus the precision positioning technology is considered much more important for its satisfaction. Therefore, available technologies for positioning within $3 \mathrm{~m}$ accuracy from the figure are Infra-Red (IR), Impulse Radio Ultra Wideband (IR-UWB), Chirp Spread Spectrum (CSS), and Radio-Frequency Identification Direct Sequence Spread Spectrum (RFID DSSS). IR-UWB technology can transmit large size data with low power by using thousands to millions times of low power pulses which occupy the frequency band of GHzs above $500 \mathrm{MHz}$, and consequently can monitor specific areas with positioning schemes as well as transmit data. Thus, it has wide range of application such as relief operations through the radio-wave detection in disastrous accidents of earthquakes [6]. CSS technology is based on spread spectrum technology, which is similar to DSSS, and is very strong in multipath fading by using Chirp signal, which sweeps the frequency band at a very high speed, as modulated pulse [7]. It can also provide a wide range of coverage with low power communication schemes.

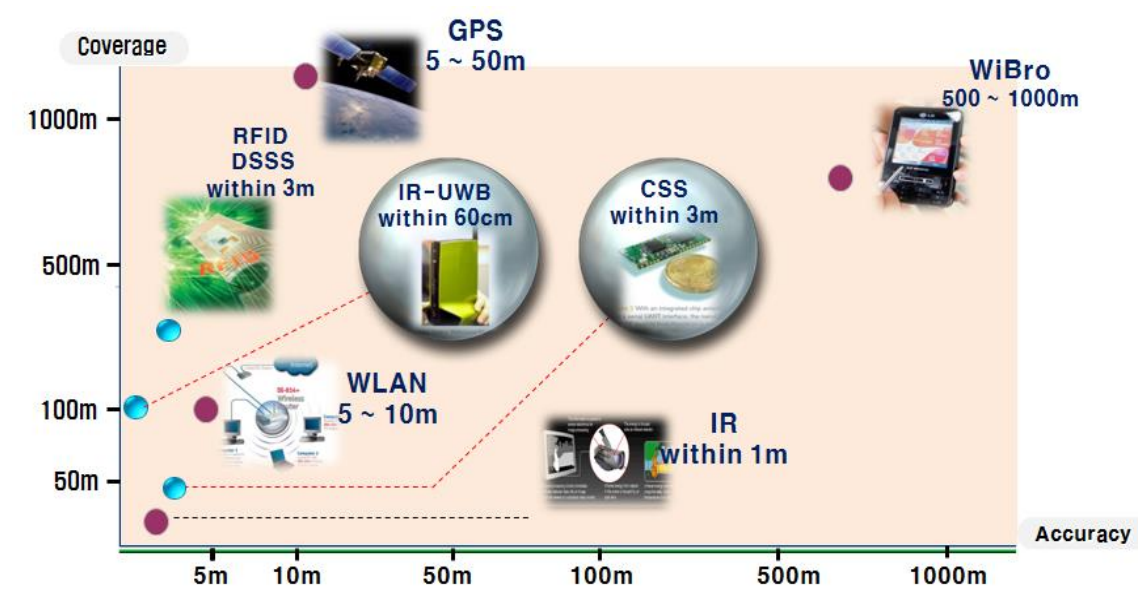

Figure 1. Ranging accuracy and Coverage among various position technologies 


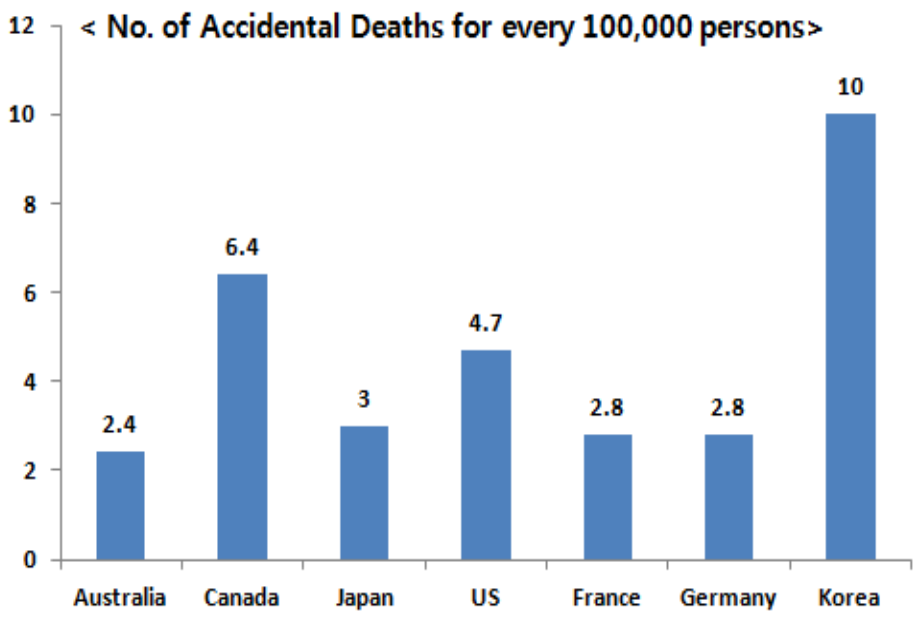

Figure 2. ILO's Estimated Deaths from Industrial Accidents

Precision positioning technologies, such as IR-UWB and CSS, could be considered as a key part of the research and development on the technology to prevent safety accidents which are sharply increasing in plants, port loading/unloading yards, construction sites, and logistics centers. Figure 2 shows the estimated deaths from industrial accidents by International Labor Organization (ILO). As shown in the figure, it is found that Korea has more deaths by 3 times than advanced countries such as Japan, France, and Germany with 10 persons for every 100,000 heads, resulted from the industrial diversification and side effects on continued industrial developments. Researches on the utilization of the positioning technology for the prevention of safety accidents or the rapid relief operations in case of accidents, and the retention of workers' safety and reduction of industrial accidents in dangerous areas by using raging-based 3D geo-spatial information estimation technology in order to have more rapid and accurate position information, have been actively conducted $[8,9]$.

In Section 2, patent analysis scope and analysis process are described. In Section 3, current patent application status for positioning technology is analyzed, and vacant technologies are presented. Finally, our concluded remarks are summarized in Section 4.

\section{Patent Analysis Scope and Process Description}

\subsection{Definition of Technologies}

Among positioning technologies for safety accidents prevention in dangerous areas and relief operations, the IR-UWB and the CSS, which provides the most precise positioning performance among considered technologies, were selected as major technologies for the patent analysis in this study, and then it was classified into 1) IRUWB, 2) CSS, 3) Convergence of UWB and CSS, 4) Other positioning technologies. The patent analysis was performed by selecting key technology elements of individual technologies, and others positioning technologies except for IR-UWB and CSS were classified as other positioning technologies. Table 1 is the summary of technology scope and data collection range. 


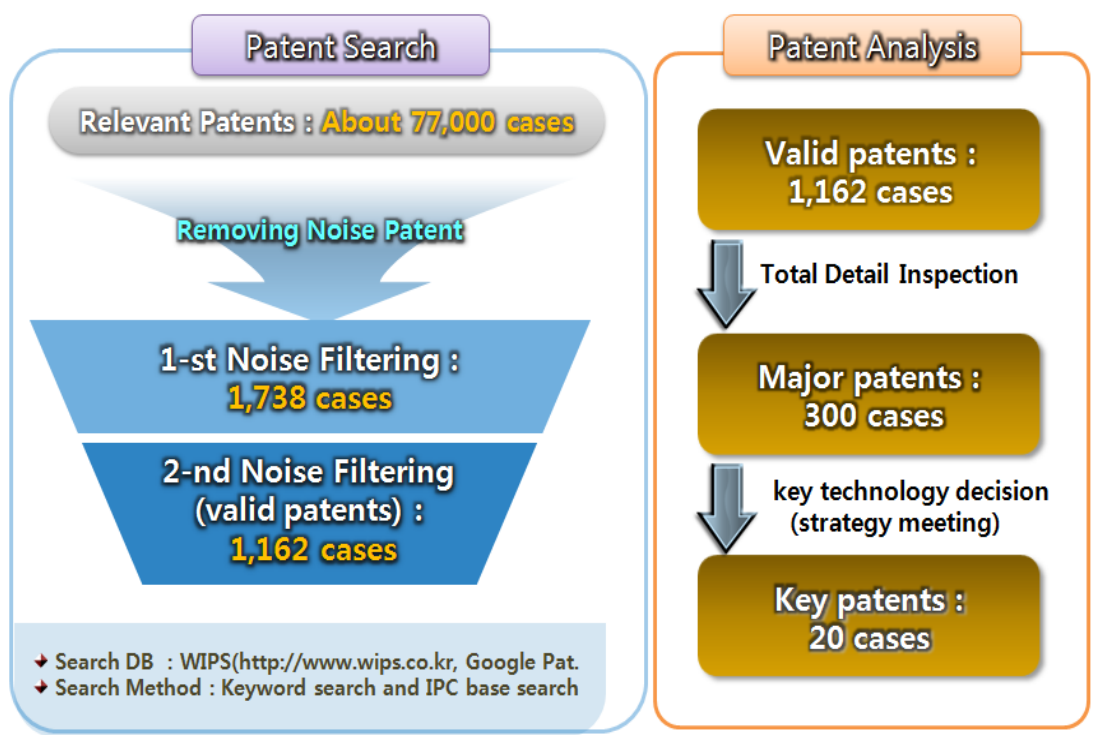

Figure 3. Patent analysis process and No. of patents by the process

Table 1. Range of Technology scope and Data collection

\begin{tabular}{|c|c|c|}
\hline $\begin{array}{l}\text { Classification- } \\
1 \text { (1-st level) }\end{array}$ & $\begin{array}{l}\text { Classification-2 } \\
\text { (2-nd level) }\end{array}$ & Technology Range \\
\hline \multirow{8}{*}{ IR-UWB } & $\begin{array}{l}\text { Orthogonal pulse } \\
\text { generation }\end{array}$ & $\begin{array}{l}\text { Developing (multi-) orthogonal pulse set which satisfies cross-correlation } \\
\text { with reference pulse in accordance with IEEE } 802.15 .4 \text { a standard. }\end{array}$ \\
\hline & $\begin{array}{l}\text { Signal detection } \\
\text { method }\end{array}$ & hybrid modulation/demodulation, signal detection technology \\
\hline & $\begin{array}{l}\text { Transmitter- } \\
\text { receiver structure }\end{array}$ & $\begin{array}{l}\text { UWB transmitter/receiver, high speed signal detection, high precision } \\
\text { signal detection, high speed signal transmission system }\end{array}$ \\
\hline & $\begin{array}{l}\text { Geopositional info. } \\
\text { estimation }\end{array}$ & Measuring indoor/outdoor (3D) positions of objects by using UWB \\
\hline & Antenna placement & $\begin{array}{l}\text { Analyzing positioning performance according to cross array antenna } \\
\text { structure and arrangement }\end{array}$ \\
\hline & $\begin{array}{l}\text { Low power } \\
\text { positioning }\end{array}$ & $\begin{array}{l}\text { Low power (energy-saving) positioning by using freedom degree of } \\
\text { shape, Low power consumption UWB transmitter/receiver }\end{array}$ \\
\hline & $\begin{array}{l}\text { Positioning } \\
\text { algorithm }\end{array}$ & $\begin{array}{l}\text { Developing integrated adaptive algorithm by AOA and TOA, High } \\
\text { precision positioning technology based on AOA, TOA, TDOA }\end{array}$ \\
\hline & $\begin{array}{l}\text { Wireless access } \\
\text { standards }\end{array}$ & Multi-user access technology \\
\hline \multirow{4}{*}{ CSS } & $\begin{array}{l}\text { Signal detection } \\
\text { method }\end{array}$ & CSS signal detection \\
\hline & $\begin{array}{l}\text { Transmitter- } \\
\text { receiver structure }\end{array}$ & $\begin{array}{l}\text { CSS transmitter/receiver, high speed signal detection, high precision } \\
\text { signal detection, high speed signal transmission system }\end{array}$ \\
\hline & $\begin{array}{l}\text { Geopositional info. } \\
\text { estimation }\end{array}$ & $\begin{array}{l}\text { Precisely measuring indoor/outdoor (3D) positions of objects by using } \\
\text { CSS }\end{array}$ \\
\hline & $\begin{array}{l}\text { Positioning } \\
\text { algorithm }\end{array}$ & $\begin{array}{l}\text { Developing integrated adaptive algorithm by AOA and TOA, High } \\
\text { precision positioning technology based on AOA, TOA, TDOA }\end{array}$ \\
\hline
\end{tabular}




\begin{tabular}{|c|c|c|}
\hline & $\begin{array}{l}\text { Wireless access } \\
\text { standards }\end{array}$ & Multi-user access technology \\
\hline \multirow{5}{*}{$\begin{array}{l}\text { UWB+CSS } \\
\text { Convergence }\end{array}$} & Error correction & High precision ranging and positioning error correction technology \\
\hline & $\begin{array}{c}\text { Convergence } \\
\text { transmitter-receiver } \\
\text { structure }\end{array}$ & $\begin{array}{l}\text { UWB+CSS convergence transmitter/receiver, high speed signal } \\
\text { detection, high precision signal detection, high speed signal transmission } \\
\text { system }\end{array}$ \\
\hline & $\begin{array}{l}\text { Convergence } \\
\text { modulation }\end{array}$ & UWB+CSS convergence signal modulation technology \\
\hline & $\begin{array}{l}\text { Signal detection } \\
\text { method }\end{array}$ & UWB+CSS convergence signal generation, detection technology \\
\hline & $\begin{array}{l}\text { Low power } \\
\text { geopositional info. } \\
\text { estimation }\end{array}$ & $\begin{array}{l}\text { Developing integrated adaptive algorithm by AOA and TOA, High } \\
\text { precision positioning technology based on AOA, TOA, TDOA }\end{array}$ \\
\hline \multirow{2}{*}{$\begin{array}{l}\text { Other } \\
\text { positioning }\end{array}$} & 2D positioning & High precision ranging, positioning technology otherthan UWB andCSS \\
\hline & 3D positioning & High precision ranging, positioning technology otherthan UWB andCSS \\
\hline
\end{tabular}

\subsection{Patent analysis process}

Figure 3 shows the diagram for patent analysis process, and demonstrates a series of processes and the number of reviewed patent analyses from patent search to select key patents. The more detailed description is as follows:

\subsubsection{Patent search}

For patent analysis, search formulas were made by using selected keywords, International Patent Classification (IPC), and major applicants under the agreement of industry-university experts and patent analysis experts, and patents of Korea (KR), US (US), Japan (JP), and Europe (EP) were searched by using following engines:

(1) WIPS search engine

(http://search.wips.co.kr/: chargeable),

(2) United States Patents and Trademarks Office search engine

(http://patft.uspto.gov/netahtml/PTO/search-bool.html: non-chargeable),

(3) Japan Patent Office search engine

(http://www19.ipdl.inpit.go.jp/PA1/cgi-bin/ PA1INIT?1294185544453:non-chargeable)

(4) Google Patents

(http://www.google.com/patents:non-chargeable)

Search formula (in English)

- (locat* or position* or navigat* or ranging*) and (UWB* or 802.15* or (ultra* and wideband*))

In this study, searches were conducted with the limitation to patents applied after 2000.01.01

by considering the cycle of the rapidly changing positioning technology. 


\subsubsection{Selection of valid patents through noise filtering}

After acquiring data integrity through redundancy check, valid patents were selected on entire searched patents by performing the 1st filtering to remove inconsistent (noise) patents, and by performing the 2 nd filtering to classify and remove patents having low relevancy.

\subsubsection{Selection of key patents}

Key patents for in-depth analysis were selected by sorting out major patents which has high relevancy through individual patent reviews and then getting consents from technical experts.

\section{Results of Patent Search}

\subsection{Valid patent search results}

By searching patents with search formulas and performing filtering process such as the removal of noise, 1,162 patents were selected for the 1st analysis from 78,051 patents, which were initially searched. Table 2 shows the number of valid patents selected through 1 st and 2nd filtering according to the patent office of each country and period. Total 1,162 valid patents were selected, which composed of 307 in (Korean Intellectual Property Office (KIPO), 110 in Europe Patent Organization (EPO), 132 in Japan Patent Office, and 613 in United States Patents and Trademark Office (USPTO), respectively.

\subsection{Deduction of vacant technology area}

\subsubsection{No. of patent applications by the 1-st level classification}

Figure 4 shows the distribution of patent applications of UWB-based, CSS-based, UWBCSS based convergence, and other position technologies, and describes great differences in no. of patent applications. As shown in the figure, several applicants have many patents for UWB-based positioning technology. Time Domain has the most 37 cases, while Samsung Electronics has 24 cases and Thales, ETRI Mitsubishi, Sony, and Inha University have rather less patents. For CSS-based positioning technology, relatively small number of applicants participates in patent application. Most of applicants, such as Samsung Electronics' 9 cases, ETRI's 7 cases, Inha University's 3 cases and so on, are Koreans, and Thales and Sony have just one case. According to Figure 4, we are able to confirm UWB-based and CSS-based positioning technologies are applied respectively as patents by multi-applicants. However, it is shown that the convergence technology of both is not pre-occupied yet.

Table 2. No. of valid patents by the country (patent office)

\begin{tabular}{c|c|c|c}
\hline \multirow{2}{*}{ Classification } & Country & Total Analysis Period & No. of Valid Patents \\
\hline \multirow{2}{*}{$\begin{array}{c}\text { Publication patents } \\
\text { (as of application date) }\end{array}$} & Korea (KIPO) & $' 00.01 \sim^{\prime} 10.10$ & 307 \\
\cline { 2 - 4 } & Europe (EPO) & '00.01 '10.10 & 110 \\
\cline { 2 - 4 } $\begin{array}{c}\text { Registered patents } \\
\text { (as of registration date) }\end{array}$ & JS (USPTO) & $\prime 00.01 \sim^{\prime} 10.10$ & 613 \\
\hline
\end{tabular}




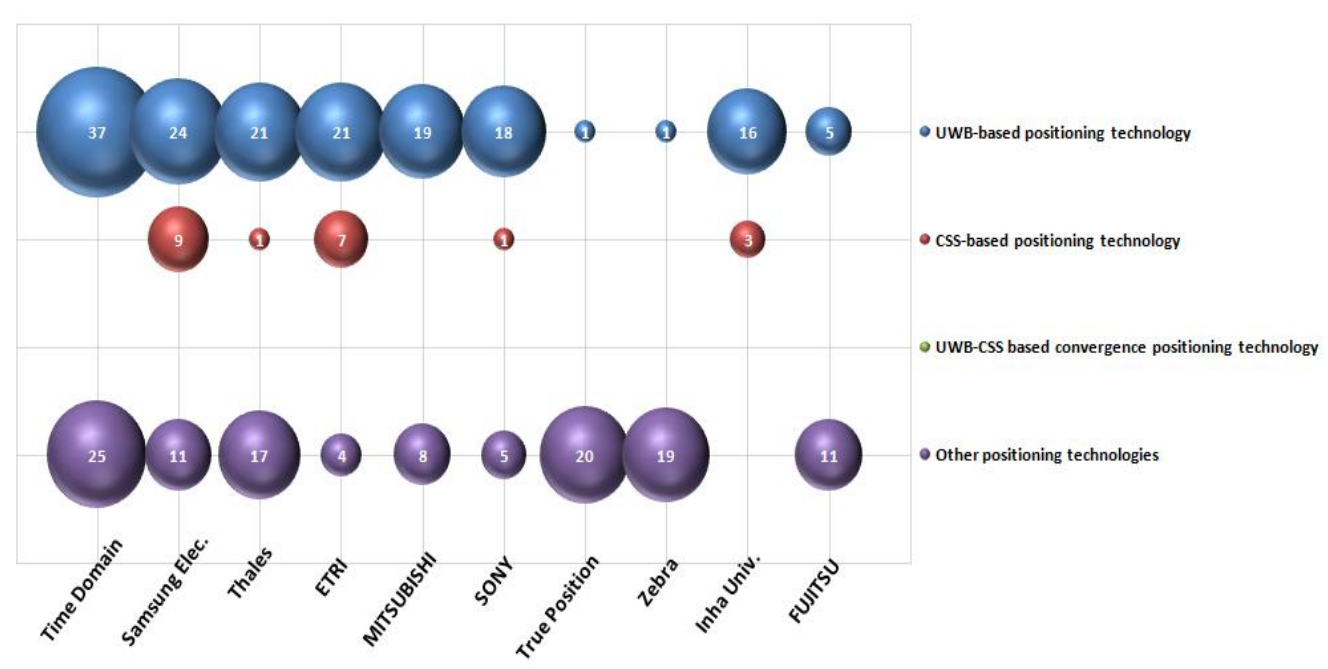

Figure 4. No. of patent applications by the 1-st level classification

\subsubsection{No. of patent applications by the 2-nd level classification}

Figure 5 represents the number of patents according to 2-nd level classification and technology range in the bubble form. The interpretation of figure can be summarized as follows:

(1) In 2002, 2006 and 2008 respectively, the seven patents for the pulse shape formation technology were applied, and a small number of patents have been maintained without a sharp increase or decrease in other years.

(2) In 2004, the number of patent applications for the signal detection method is increased, and then more than ten patents a year have been steadily applied.

(3) For the transmitter/receiver structure, since 17 patents were applied in 2003, many ones have been steadily applied till 2008.

(4) (4) For the geo-spatial information estimation technology, a relatively smaller number of applications have been made than compared with other technical sector. Note that the most three applications were made in 2007.

(5) For the antenna placement technology, as the patent application was initiated in 2002, average 3 4 patents have been applied till 2009, judging from relatively more applications in 2009 , the application can be forecasted to increase in the future.

(6) For the low power positioning technology, the increase in application has not been seen since the six patents were applied in 2006.

(7) For the positioning algorithm, the number of applications is rapidly increased in 2007 $\sim 2008$.

(8) For the wireless access standards, so many applications have not been applied except the seven patents being applied in 2007. 
From the Figure 5, it is found that patents application of geo-spatial information estimation technology, antenna placement technology, low power positioning technology, and wireless access standards are relatively less.

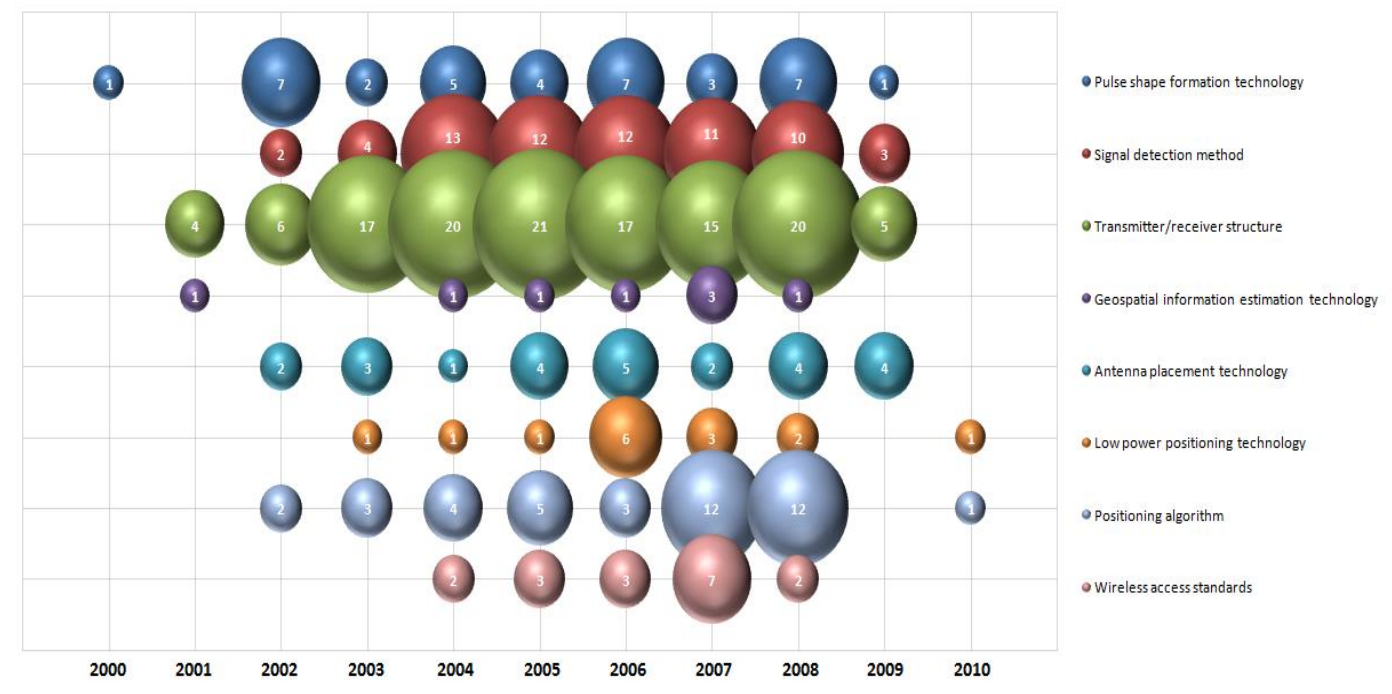

Figure 5. No. of patent applications by 2-nd level classification and year

This could be interpreted that they are key elements composing of positioning technologies, but they are able to be defined as the vacant technology which are not actively pre-occupied yet by patent applications. However, it is inadequate to conclude that their additional patent applications to the fiercely competitive technological fields such as transmitter/receiver structure and positioning algorithm which have been already filled with many patent applications are inappropriate. Considering the characteristic of patent reflecting market situation, they can be considered as key technologies required in the market with high expectations to make profits so much, and thus their applications might be appropriate.

\subsubsection{Technology Flow-Chart}

Figure 6 shows the flow of changing technologies according to the patent application year based on 2-nd level classification. The expected technologies for applications can be estimated by reviewing the yearly flow of changing technologies and the hardware trend reflected with these technologies.

If 20 key patents are arranged in chronological order and grouped based on characteristics by patent, they can be classified as follows:

(1) Technology for precise positioning under NLOS channel environment such as multipath 
(2) Multi-antenna based precise positioning technology

\begin{tabular}{|c|c|c|c|c|c|c|c|c|}
\hline "00 & ०01 & '02 & "03 & '05 & ०06 & "07 & "08 & Estimated \\
\hline \multirow[t]{2}{*}{ 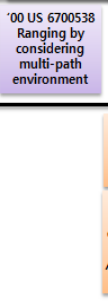 } & & & & \multicolumn{2}{|c|}{ 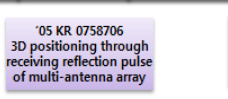 } & \multicolumn{2}{|c|}{ 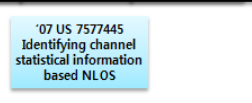 } & $\begin{array}{l}\text { Multi-path environment } \\
\text { analysis High precision } \\
\text { positioning }\end{array}$ \\
\hline & 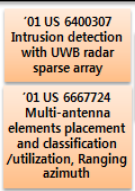 & 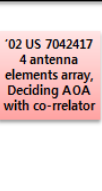 & $\begin{array}{l}\text { O3 EP } 15733353 \\
\text { Ranging distance } \\
\text { between soree } \\
\text { than 3receiving } \\
\text { antenas and } \\
\text { Positioning with } \\
\text { TDOA }\end{array}$ & 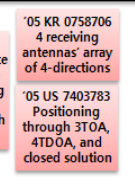 & & \multicolumn{2}{|l|}{ 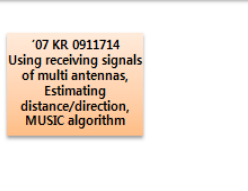 } & $\begin{array}{l}\text { Multi-antenna based } \\
\text { high performance } \\
\text { positioning }\end{array}$ \\
\hline \multirow[t]{2}{*}{ 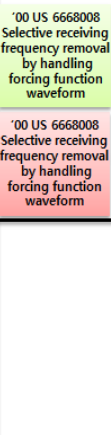 } & 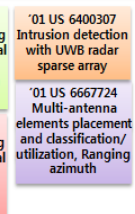 & & 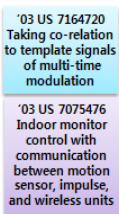 & & & & 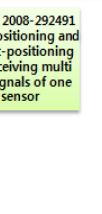 & $\begin{array}{l}\text { Signal detection } \\
\text { performance } \\
\text { improvement }\end{array}$ \\
\hline & & & $\begin{array}{c}03 \text { EP } 1573353 \\
\text { Ranging distance } \\
\text { between more } \\
\text { than } 3 \text { receiving } \\
\text { antennas and } \\
\text { Positioning with } \\
\text { TDOA }\end{array}$ & $\begin{array}{l}\text { '05 Us } 7403783 \\
\text { Positioning } \\
\text { through 3ToA, } \\
\text { 4ToOA and } \\
\text { dosed solution } \\
\end{array}$ & 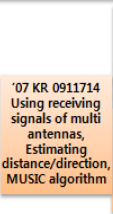 & 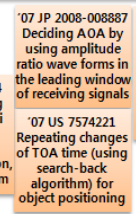 & 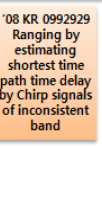 & $\begin{array}{l}\text { Hybrid positioning } \\
\text { algorithm-based } \\
\text { high precision/high } \\
\text { speed positioning }\end{array}$ \\
\hline
\end{tabular}

Figure 6. Technology flow of key patents

(3) Signal processing technology using frequency removal, template signal, sensor technology

(4) Technology to improve precision by applying a plurality of positioning algorithms, depending on the annual interest technology the technology area requiring future application can be forecast.

Through this study, technologies of 1) high precision positioning based on multi-path environment analysis, 2) multi-antenna based high precision positioning, 3) signal detection performance improvement, and 4) hybrid positioning algorithm-based high precision, high speed positioning were estimated to be the direction of the patent application in the future

\section{Conclusions}

In this study, IR-UWB and CSS technologies, which are available for the precision positioning among various positioning technologies, were analyzed from the patent perspective, and the vacant technology area that is required to research and development in the future was drawn as conclusion.

Although the positioning patent application of IR-UWB has been more active than that of CSS, it is limited to the patent application using individual technologies of their own, and so the technology to improve positioning accuracy through the convergence between IR-UWB and CSS was analyzed as a vacant technology area. In addition, the geo-spatial information estimation technology and the low power positioning technology were concluded as vacant technology areas to be actively researched and developed in the future among required element technologies in order to realize the positioning technology using IR-UWB.

Vacant technologies through the yearly changing technology flow and the hardware trend were estimated as high precision positioning based on multi-path environment analysis, multi- 
antenna based high performance positioning, signal detection performance improvement, and hybrid positioning algorithm-based high precision, high speed positioning technology.

Synthetically, vacant technology areas required for research and development in the future can be represented by the precision and speed up of positioning, utilization technology of multiple transmitters-receivers, and convergence of multi-technologies.

\section{Acknowledgements}

This research was supported by the Basic Science Research Program through the National Research Foundation of Korea (NRF), funded by the Ministry of Education (NRF2013R1A1A2005157).

\section{References}

[1] Y. Cho, S. Cho, B. Kim, S. Lee, J. Lim and W. Choi, "Indoor/outdoor seamless positioning technology trend", Analysis of Electronic Communications Trend., vol. 22, (2007).

[2] M. Matosevic, Z. Salcic and S. Berber, "A Comparison of Accuracy Using a GPS and a Low-Cost DGPS", IEEE Transactions on Instrumentation and Measurement, vol. 55, no. 5, (2006).

[3] G. Sato, T. Asai, T. Sakamoto and T. Hase, "Improvement of the positioning accuracy of a software-based GPS receiver using a 32-bit embedded microprocessor", IEEE Transactions on Consumer Electronics, vol. 46, no. 3, (2000).

[4] N. Chang, R. Rashidzadeh and M. Ahmadi, "Robust indoor positioning using differential Wi-Fi access points", IEEE Transactions on Consumer Electronics, vol. 56, no. 3, (2010).

[5] V. K. Jain, S. Tapaswi and A. Shukla, "Location estimation based on semi-supervised locally linear embedding (SSLLE) approach for indoor wireless networks", Wireless Personal Communications, vol. 67, no. 4, (2002).

[6] B. Allen, T. Brown, K. Schwieger, E. Zimmermann, W. Malik, D. Edwards, L. Ouvry and I. Oppermann, "Ultra wideband: Applications, technology and future perspectives", 2005 International Workshop on Convergence Technologies (IWCT), (2005) June 6-10; Oulu, Finland.

[7] IEEE 802.15 WPAN Low Rate Alternative PHY Task Group 4a, "PART 15.4: Wireless Medium Access Control (MAC) and Physical Layer (PHY) Specications for Low-Rate Wireless Personal Area Networks (LRWPANs)", Draft P802.15.4a/D7, (2007) March.

[8] J. Hightower, R. Want and G. Borriello, "Spoton: An Indoor 3d Location Sensing Technology Based on RF Signal Strength”, Technical Report 00-02-02, University of Washington, Seattle, (2000).

[9] G. Kantor and S. Singh, "Preliminary Results in Range-Only Localization and Mapping", 2002 IEEE Conf. on Robotics and Automation, (2002) May 11-15; Washington D.C., U.S.A.

\section{Authors}

Hangwon Lee received the B.S. and M.S. degrees in electronics engineering from Gangneung-Wonju National University, Korea in 2007. He is currently working toward the $\mathrm{Ph} . \mathrm{D}$. degree at the Kwangwoon University. His research interests include ultra-wideband systems, high precision positioning techniques and patent analysis.

Youngok Kim received the B.S. degree in mechanical engineering from Yonsei University, Seoul, Korea in 1999, and the M.S. and Ph.D. degrees in electrical and computer engineering from the University of Texas at Austin, Austin, in 2002 and 2006, respectively. From 2006 to 2008, he was a senior researcher at Infra Laboratory of Korea Telecom (KT), Seoul, Korea. In March 2008, he joined the Department of Electronic Engineering of Kwangwoon University, Seoul, Korea, as a faculty member. His research interests include ultra-wide band wireless communication systems, OFDM-based systems, precise ranging and location systems, PAPR reduction techniques, diversity techniques for wireless systems, multiple-access schemes in multicarrier systems, and patent analysis. 